
SUSUNAN DEWAN REDAKSI

“JURNAL NASIONAL KOMPUTASI DAN TEKNOLOGI INFORMASI (JNKTI)"

\author{
Penanggung Jawab \\ Muhammad Fadhli, S.Kom, M.Kom \\ Ketua Dewan Editor \\ Zulfan, ST, MT \\ Editor Pelaksana \\ Munawir, ST, MT \\ Baihaqi, ST, MT \\ Sekretaris \\ Yeni Yanti, ST, MT \\ Mitra Bestari \\ Prof. Dr. Ir. Yuwaldi Away, M.Sc \\ Dr. Taufiq A. Gani, S.Kom, M.Eng.Sc \\ Dr. Melinda, ST, M.Sc \\ Layout \\ Eka Novendra, ST \\ Penerbit \\ Program Studi Teknik Informatika \\ Universitas Serambi Mekkah \\ Alamat Penerbit
}

Gedung H Fakultas Teknik Universitas Serambi Mekkah

Jl. T. Imum Lueng Bata, Telp. (0651)26160 Batoh - Banda Aceh 


\section{SINOPSIS}

Jurnal Nasional Komputasi dan Teknologi Informasi (JNKTI) merupakan jurnal ilmiah nasional yang diterbitkan oleh Program Studi Teknik Informatika Universitas Serambi Mekkah yang mempublikasikan artikel-artikel ilmiah dalam bidang komputasi dan teknologi informasi.Jurnal ini terbit sebanyak 2 (dua) kali dalam 1 (satu) tahun yaitu pada Bulan April dan Oktober. Bidang-bidang fokus penelitian yang akan dipublikasi dalam jurnal ini antara lain :

- Bidang Rekayasa Perangkat Lunak

- Bidang Jaringan Komputer

- Bidang Multimedia dan Pengolahan Citra Digital

- Bidang Komputasi

- Multidisiplin ilmu lainnya yang relevan 
DAFTAR ISI

JNKTI VOL.2 NO.1, APRIL 2019

Studi Simulasi Aerodinamika Airfoil dan Prediksi

$1-8$

Performa Picth Tetap Turbin Angin Poros Tegak (Darrieus)

terhadap Output Power untuk Aplikasi Kecepatan Angin Rendah

Wahyu Priyanto ${ }^{1}$, Ira Devi Sara ${ }^{2}$, Rakhmad Syafutra Lubis ${ }^{3}$

Analisis Performansi Video Streaming Dengan Menggunakan

$9-12$

Protokol RTSP Pada Jaringan IEEE 802.11n

Rahmad Rizki ${ }^{1}$, Rizal Munadi ${ }^{2}$, Syahrial $^{2}$

Pengaruh Heatsink Terhadap Kinerja Modul Surya

$13-18$

T. Mizan Sya'rani D. ${ }^{1 *}$, Ira Devi Sara ${ }^{2}$, dan Laina Hilma Sari ${ }^{3}$

Penentuan Tingkat Penyebaran Ikan Berdasarkan Citra

Suhu Permukaan Laut Di Perairan Laut Kabupaten Aceh Jaya

Menggunakan Satelit Aqua Modis

Naziran ${ }^{1}$, Rizal Munadi ${ }^{2}$, Muchlisin ${ }^{2}$

Studi Pengaruh Hibridisasi Seleksi Roullete Wheel Dengan $26-30$

Tournament Selection Menggunakan Algoritma Berevolusi Pada TSP

Cut lilis Setiawati ${ }^{1}$, Taufiq Abdul Gani ${ }^{2}$, Yuwaldi Away ${ }^{2}$

Audit Dan Optimasi Energi Listrik Pada Bangunan Kampus $31-37$

Menggunakan Metode Algoritma Genetika

Samsuddin $^{1}$, Suriadi ${ }^{2}$, Yuwaldi Away ${ }^{3}$

Aplikasi Histogram Discrete Cosine Transform (DCT) Untuk $38-42$

Sistem Temu Kembali Citra Termal Berbasis Konten

Faridah $^{1}$, Khairul Munadi ${ }^{2}$, Fitri Arnia ${ }^{3}$

Pengujian Algoritma Artificial Neural Network (ANN) $43-47$

Untuk Prediksi Kecepatan Angin

Syukri $^{1}$, Samsuddin ${ }^{2}$

Penerapan Information Retrieval Menggunakan Pemodelan $48-54$

Topik Pada Deskripsi Portal Multimedia

Indra Gita Anugrah ${ }^{1}$ dan Harunur Rosyid ${ }^{2}$

Analisa Steganografi untuk Citra Bewarna (RGB)

Menggunakan Metode Less Significant Bit (LSB)

Raihan Islamadina $^{1}$, Baihaqi $^{2}$, dan Mauzar sulistriadi ${ }^{3}$ 


\title{
Studi Pengaruh Hibridisasi Seleksi Roullete Wheel Dengan Tournament Selection Menggunakan Algoritma Berevolusi Pada TSP
}

\author{
Cut lilis Setiawati ${ }^{1}$, Taufiq Abdul Gani², Yuwaldi Away ${ }^{2}$ \\ Magister Teknik Elektro, Universitas Syiah Kuala \\ ${ }^{1}$ cutlilissetiawati@gmail.com,
}

\begin{abstract}
Abstrak - Permasalahan optimalisasi sering kita jumpai dalam sehari-hari yang dilakukan oleh seseorang maupun kelompok, aktivitas seorang salesman yang selalu dijalankan diantaranya melakukan perjalanan untuk mengunjungi beberapa kota untuk menjajakan dagangannya, jasa transportasi dan lain-lain. Proses perjalanan salesman dan transportasi yang dilakukan merupakan salah satu bentuk dari optimalisasi, yaitu bagaimana mengoptimalkan jalur dalam menempuh perjalanan. Perkembangan teknologi informasi dalam bidang komputasi saat ini semakin menjanjikan, permasalahan optimalisasi dapat dioptimalkan sehingga dapat memberikan solusi yang lebih optimal dengan menerapkan pemodelan optimasi ke dalam aplikasi komputer untuk dapat menyelesaikan permasalahan Travelling Salesman Problem (TSP). Algoritma berevolusi masih dianggap sangat baik dalam menyelesaikan masalah yang kompleks, tetapi pada penerapannya algoritma berovolusi tidak begitu baik dalam menyelesaikan masalah yang terlalu kompleks dengan jalur pencarian ratusan hingga ribuan bahkan jutaan kota yang akan dikunjungi oleh salesman. Penentuan jalur terpendek sangat tergantung pada proses seleksi yang digunakan dalam algoritma berevolusi. Penelitian ini bertujuan untuk membandingkan metode seleksi Roullete Wheel dengan Tournament Selection pada algoritma berevolusi dan menggabungkan metode seleksi Roullete Wheel dengan Tournament Selection untuk menghasilkan metode seleksi baru yang dapat diterapkan pada algoritma berevolusi dalam permasalahan Travelling Salesman Problem (TSP). Setelah melakukan penelitian, maka dapat disimpulkan bahwa implementasi Turnament Selection memiliki nilai lebih optimal dibandingkan dengan seleksi Roullete Wheel, perbandingan nya sebesar 44\% lebih bagus dengan menggunakan Tournament Selection, dari hasil hibridisasi kedua metode Roullete Wheel dengan Tournament selection dapat menghasilkan solusi yang lebih optimal.
\end{abstract}

Kata Kunci : perbandingan metode seleksi, kombinasi metode seleksi, hibridisasi roullete wheel dengan turnament selection.

\begin{abstract}
We often encounter optimization problems in a day-to-day activity carried out by a person or group, the activities of a salesman who is always being run include traveling to visit several cities to sell merchandise, transportation services and others. The process of traveling salesmen and transportation carried out is one form of optimization, namely how to optimize the path of travel. The development of information technology in the field of computing is now more promising, optimization problems can be optimized so that it can provide a more optimal solution by applying optimization modeling into computer applications to be able to solve the problems of Traveling Salesman Problem (TSP). Evolved algorithms are still considered to be very good at solving complex problems, but in the application of an innovative algorithm is not very good at solving problems that are too complex with a search path of hundreds to thousands and even millions of cities that will be visited by salesmen. Determination of the shortest path depends on the selection process used in the evolving algorithm. This study aims to compare the Roullete Wheel selection method with Tournament Selection in the evolved algorithm and combine the Roullete Wheel selection method with Tournament Selection to produce a new selection method that can be applied to the evolved algorithm in the problem of Traveling Salesman Problem (TSP). After doing the research, it can be concluded that the implementation of the Selection Tournament has a more optimal value compared to the Roullete Wheel selection, from the results of the second hybridization of the Roullete Wheel method with Tournament selection can produce a more optimal solution.
\end{abstract}

Keywords: comparison of selection methods, combination of selection methods, hybridization of roulette wheel with turnament selection.

\section{Pendahuluan}


Permasalahan optimalisasi sering kita jumpai dalam sehari-hari yang dilakukan oleh seseorang maupun kelompok, aktivitas seorang salesman yang selalu dijalankan diantaranya melakukan perjalanan untuk mengunjungi beberapa kota untuk menjajakan dagangannya, jasa transportasi dan lain-lain. Traveling Salesman Problem (TSP) merupakan suatu permasalahan optimalisasi yang dapat diterapkan pada berbagai kegiatan seperti perjalanan seorang salesman, transportasi dan pengambilan surat pada setiap kotak pos. TSP bertujuan untuk mencari rute terpendek dari kota asal ke kota yang dituju dengan syarat setiap kota hanya dapat dikunjungi satu kali kecuali kota awal keberangkatan [1].

Algoritma evolusi merupakan suatu algoritma yang memiliki prinsip kerjanya berdasarkan pada proses seleksi alam. Operasinya didasarkan pada kelangsungan hidup suatu populasi sehat yang memproduksi keturunan untuk menghasilkan suatu solusi. Seleksi Roullete Wheel, metode ini sering juga dikenal dengan nama stochastic sampling with replacement. Individu-individu dipetakan dalam suatu segmen garis secara berurutan sedemikian hingga tiaptiap segmen individu memiliki ukuran yang sama dengan ukuran fitness-nya. Sebuah bilangan random dibangkitkan dan individu yang memiliki segmen dalam kawasan bilangan random tersebut akan terseleksi. Proses ini diulang hingga diperoleh sejumlah individu yang diharapkan. Metode ini menirukan permainan roulette wheel di mana masing-masing kromosom menempati potongan lingkaran pada roda raulette secara proporsional sesuai dengan nilai fitnessnya. Kromosom yang memiliki nilai fitness lebih besar menempati potongan lingkaran yang lebih besar dibandingkan dengan kromosom bernilai fitness rendah [2].

Tournament Selection merupakan salah satu metode seleksi dalam algoritma berevolusi yang populer karena efisiensi dan implementasi yang sederhana. Dalam seleksi turnament, $\mathrm{n}$ individu dipilih secara acak sebanyak jumlah populasi (popsize). Banyaknya perbandingan dalam turnamen terhadap individu disebut dengan tournament size. Individu yang terpilih dibandingkan dengan nilai fitness-nya. Nilai fitness yang lebih tinggi akan lolos menjadi generasi berikutnya. Seleksi turnamen juga memberikan kesempatan pada semua individu terpilih untuk mempertahankan keragamannya [3].

Dari pembahasan diatas, penelitian ini berkonsentrasi pada studi pengaruh hibridisasi seleksi roullete wheel dengan tournament selection menggunakan algoritma berevolusi pada Travelling Salesman Problem. Tujuan dari penelitian ini adalah untuk menggabungkan metode seleksi Roullete Wheel dengan Tournament Selection untuk meningkatkan diversity dan optimality dan menghasilkan solusi yang optimal dengan hibridisasi metode seleksi Roullete Wheel dengan Tournament Selection pada algoritma berevolusi dalam permasalahan Travelling Salesman Problem (TSP).

\section{Metodologi Penelitian}

\subsection{Objek dan alur penelitian}

Objek dalam penelitian ini adalah bidang optimasi diversity dan jarak minimum dengan melakukan simulasi komputer.

\subsection{Teknik yang digunakan}

Teknik yang digunakan pada tesis ini adalah simulasi komputer dengan menggunakan Dataset TSPLIB95 yang di unduh secara gratis [4]. Penelitian ini adalah penelitian kualitatif dengan melakukan eksperimen dalam menganalisis dan merancang perangkat lunak untuk melakukan seleksi pencarian rute terpendek dengan metode seleksi dalam algoritma evolusi pada kasus TSP. Penelitian ini dilakukan di Program Pasca Sarjana Magister Teknik Elektro Universitas Syiah Kuala Banda Aceh.

\subsection{Prosedur pengujian}

Pada penelitian ini, proses akan dilakukan empat kali pengujian dengan langkah-langkah pengujian seperti pada Gambar 1.

2.4. Algoritma gabungan Roullete wheel dan

Tournament Selection

Untuk implementasi algoritma Hibridisasi Roullete wheel dan Turnamen Selection dapat dilihat pada Gambar 2.

Berdasarkan Gambar 2 di atas maka dapat dijelaskan alur dari program utama sebagai berikut :

1. Memulai menjalankan program

2. Inputan parameter yang dimulai dengan memasukkan jumlah populasi, jumlah offserping dan jumlah generasi. Populasi yang dimaksud adalah sekumpulan individu dengan ciri-ciri yang sama (spesies) pada suatu tempat. Offspring adalah jumlah keturunan yang mewakili induknya untuk generasi berikutnya disini yang dimaksud offspring adalah kota tujuan. Sedangkan generasi jumlah kota yang akan dilalui dalam jalur yang telah dibentuk.

3. Inisialisasi populasi dilakukan untuk menghasilkan solusi awal dari suatu permasalahan algoritma genetika. Inisialisasi ini dilakukan secara acak sebanyak jumlah kromosom/populasi yang diinginkan. Selanjutnya dihitung nilai fitness-nya dan seterusnya dilakukan seleksi dengan menggunakan metode roda roullete atau tournament 
P-ISSN 2620-8342

E-ISSN 2621-3052

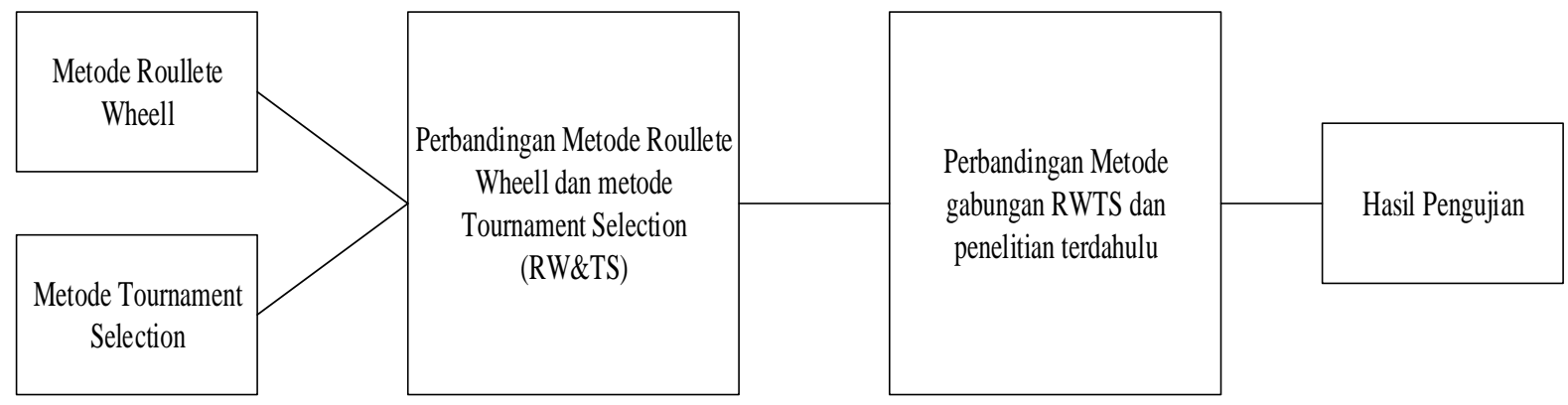

Gambar 1. Prosedur pengujian

4. Evaluasi individu adalah dimana proses ini akan menghitung nilai fitness dari setiap kromosom yang telah dibangkitkan secara random pada tahap inisialisasi populasi di atas. Nilai fitness dari setiap koromosom dihitung berdasarkan panjang jalur yang dihasilkan dari total jarak keseluruhan dari urutan node-node yang dilalui.

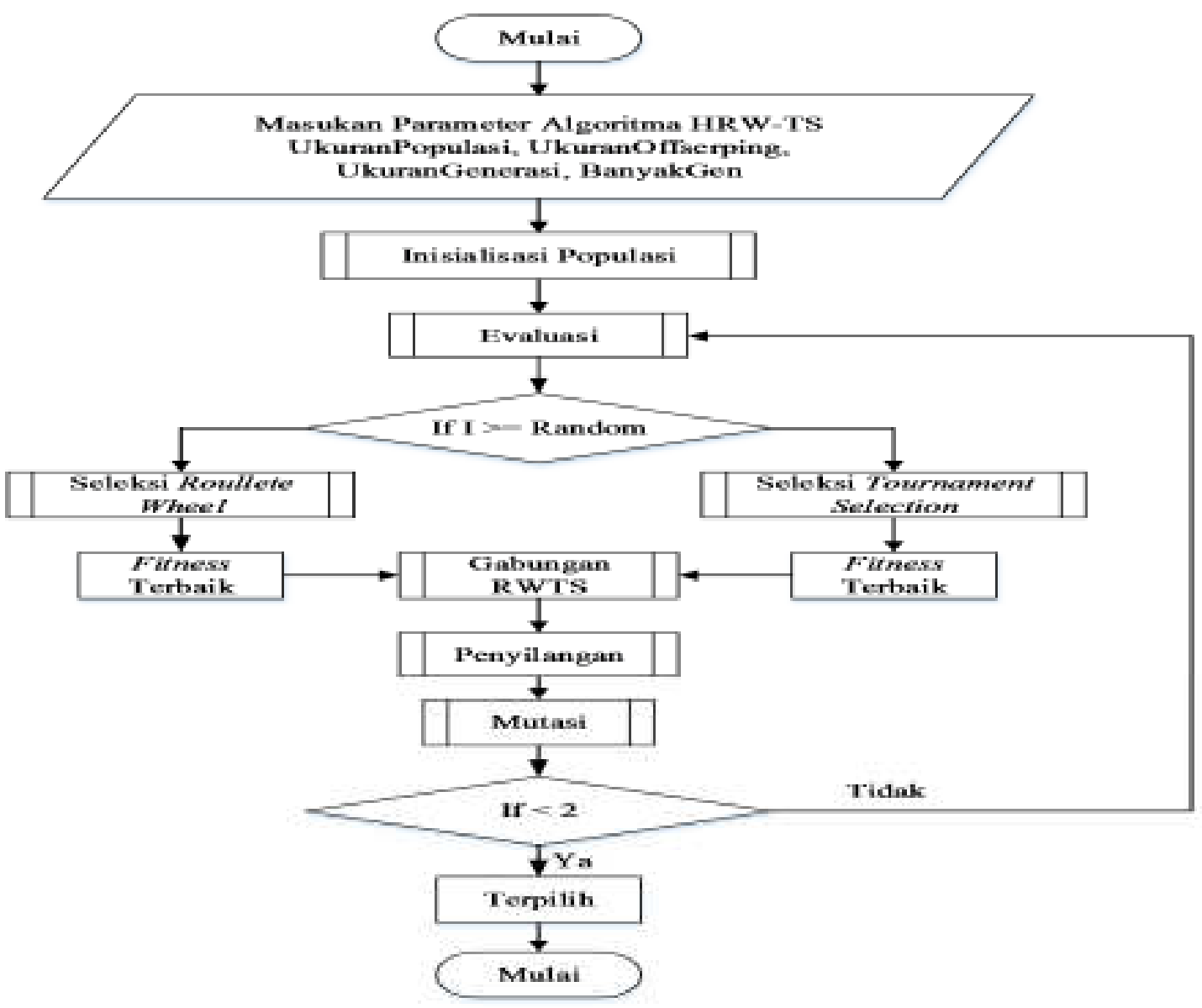

Gambar 2. Algoritma gabungan metode RW - TS 
5. Pada metode seleksi roulette wheel, orang tua dipilih berdasarkan nilai fitness-nya, semakin baik nilai fitness maka semakin besar kemungkinannya untuk terpilih. Diandaikan semua kromosom diletakkan pada sebuah roda roulette, besarnya kemungkinan bagi setiap kromosom adalah tergantung dari nilai fitnessnya. Seleksi ini bertujuan untuk memberikan kesempatan reproduksi yang lebih besar bagi anggota populasi yang memiliki fitness tinggi untuk melakukan reproduksi.

6. Pada metode seleksi tournament, akan ditetapkan suatu nilai untuk setiap individu-individu yang dipilih secara random dari suatu populasi. Individuindividu yang terbaik dalam kelompok ini akan diseleksi sebagai induk. Parameter yang digunakan pada metode ini adalah nilai yang bernilai antara 2 sampai $\mathrm{N}$ (jumlah individu dalam suatu populasi).

7. Pada tahap penyilangan ini adalah akan mengambil nilai fitness terbaik dari masing-masing seleksi, kemudian disilangkan untuk mendapatkan generasi yang lebih baik. Hasil dari penyilangan (crossover) ini akan dijadikan untuk mewakili generasi berikutnya.

8. Selanjutnya mutasi, pada tahap ini dilakukan untuk memanggil kembali gen-gen yang hilang akibat proses seleksi. Sehingga kemungkinan dapat terpilih kembali.

Tabel 1. Hasil pengujian

\begin{tabular}{|c|c|c|c|c|c|c|c|c|c|c|}
\hline \multirow{3}{*}{ No } & \multirow{3}{*}{ Kota } & \multicolumn{9}{|c|}{ Best Solution } \\
\hline & & \multicolumn{3}{|c|}{ Roullette Wheel } & \multicolumn{3}{|c|}{ Turnament Selection } & \multicolumn{3}{|c|}{ RW-TS } \\
\hline & & Min & Max & Div & Min & Max & Div & Min & Max & Div \\
\hline 1 & eil51 & 188 & 368 & 62,55 & 152 & 306 & 50 & 154 & 324 & 48,43 \\
\hline 2 & eil76 & 398 & 541 & 23,94 & 280 & 503 & 57,83 & 275 & 506 & 59,28 \\
\hline 3 & pr76 & 113619 & 157635 & 24,48 & 90972 & 133840 & 57,04 & 86862 & 133919 & 59,01 \\
\hline 4 & $\mathrm{rd} 100$ & 16172 & 21740 & 82,1 & 17911 & 24028 & 80,2 & 12517 & 15754 & 80,45 \\
\hline 5 & eil101 & 545 & 751 & 23,27 & 402 & 690 & 63,76 & 424 & 682 & 66,78 \\
\hline
\end{tabular}

9. Kemudian akan dilakukan pencarian berdasarkan keriteria jika nilai fitness tidak ada lagi yang lebih baik dari yang sekarang, maka akan berhenti dan selesai. Jika nilai fitness lebih baik dari saat ini, maka akan terus dilakukan pencarian sampai tidak ditemukan lagi yang lebih baik. Sehingga nilai fitness yang dicari akan benar-benar optimal.

\section{Hasil Dan Pembahasan}

Pada penelitian ini mengambil 3 metode yaitu roulletee wheel, tournament selection dan gabungan, kemudian di ambil nilai rata - rata jarak dan diversity. Berikut ini akan diuraikan hasil impelemntasi proses penggabungan metode roullete wheel dengan tournament selection. Pada Tabel 1 di bawah adalah hasil pengujian sebelum dan sesudah dilakukan penggabungan setiap metode pengujian pada setiap dataset diuji sebanyak 5 (lima) kali. Untuk proses penggabungan yang dilakukan adalah Pertama metode roullete wheel dijalankan terlebih dahulu pada setiap data set yang digunakan. Kedua metode tournament selection dijalan sebanyak 5 kali pada setiap dataset. Ketiga adalah proses penggabungan, pada proses penggabungan yang dilakukan dengan mengambil nilai yang terbaik dari kedua algoritma, kemudian dilakukan proses inisialisasi sampai dengan selesai sehingga hasil yang diperoleh sebagaimana pada Tabel 1 berikut ini. 


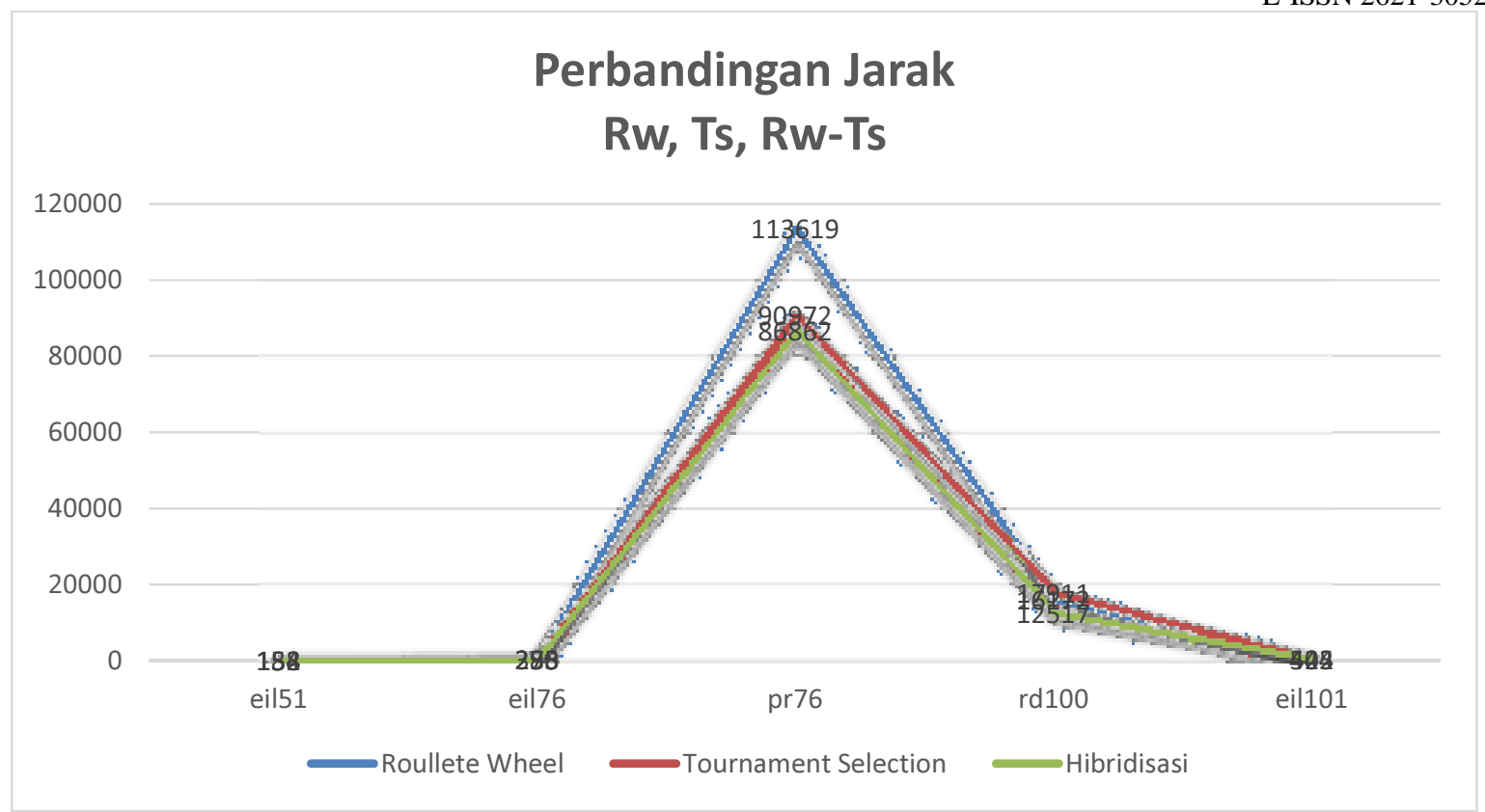

Gambar 3. Perbandingan Jarak Minimum

\section{Kesimpulan}

Berdasarkan hasil implementasi dan pembahasan maka dapat disimpulkan yaitu sebagai berikut :

1. Perbandingan metode seleksi Roullete Wheel memiliki nilai optimum 113.619 dan Tournament Selection memiliki nilai 90.972, dari nilai tersebut dapat disimpulkan bahwa untuk menghasilkan nilai lebih optimum lebih baik dengan metode Tournament selection, hasil perbandingan nya mencapai $44 \%$.

2. Penggabungan metode roullete wheel dan tournament selection menghasilkan nilai lebih optimum pada dataset yang kecil dan untuk nilai diversity lebih bagus.

\section{Daftar Pustaka}

[1]. [G. Ramani, N. Bouvanasilan, Seenuvasan, and V. Seenuvasan, "A Perspective View on Travelling Salesman Problem using Genetic Algorithm," Nature \& Biologically Inspired Computing. NaBIC World Congress IEEE International Conference on, vol., no., pp.356,361, 9-11 Dec. 2009.

[2]. Munawir., "Komparasi strategi pergantian steady state dan generational pada algoritma berevolusi dalam penyelesaian travelling salesman problem (TSP)," Tesis, Universitas Syiah Kuala, 2016

[3]. Zne-Jung Lee, "A hybrid algorithm applied to travelling salesman problem" Networking, Sensing and Control, 2004 IEEE International
Conference, vol. 1, no.pp.237,242 Vol. 1, 21-23 March 2004.

[4]. Data TSPLib [Online] : http//www.iwr.uni.heidelberg.de/groups/comopt/ software/TSP Lib95, di akses 20 Februari 2016.

[5]. Fitriyani ,Y Away, T Abdul Gani, Pengaruh Inisialisasi Populasi Random Search pada Algoritma Berevolusi dalam Optimasi Travelling Salesman Problem (Tsp). Jurnal Nasional Komputasi dan Teknologi Informasi (JNKTI), 1(2), Oktober 2018.

[6]. Munawir, TA. Gani, Penggabungan Metode Replacement Strategy Steady State dan Generational Dalam Algoritma Berevolusi untuk Penyelesaian TSP. Jurnal Serambi Engineering. 1(2), 2017

[7]. Erdiwansyah, Munawir, R. Islamadina. Analisis Hibridisasi Pencarian Lokal Dengan Populasi Dalam Travelling Salesman Problem (TSP). Jurnal Serambi Engineering, 2(4), 2017

[8]. Munawir, TA. Gani, Y. Away, Implementasi Replacement Strategy Steady State Dan Generational Dalam Algoritma Berevolusi Untuk Penyelesaian TSP. Karya Ilmiah Teknik Elektro, 1(1), 2016 
